\title{
Laboratory control of heparin therapy
}

\author{
M. J. O'SHEA ${ }^{1}$, P. T. FLUTE, AND G. M. PANNELL \\ From the Department of Haematology, King's College Hospital and Medical School, London
}

SYNOPSIS The effect of heparin therapy was followed in 50 patients treated for thrombo-embolic disease. Individual response to a standard dose of 40,000 units of heparin daily showed a considerable variation and the effect was not constant on subsequent days. Five of the 50 patients developed a serious haemorrhage.

It is proposed that to ensure the adequacy of treatment detectable levels of heparin should be obtained but because of the high risk of bleeding these levels should not be excessive.

The results suggest that control of heparin therapy can be based on the thrombin clotting time. Using this test it is advised that treatment is monitored daily in order to achieve a plasma heparin level of up to $1 \mathrm{mg}$ per $100 \mathrm{ml}$.

As a potent anticoagulant heparin has been used therapeutically for over 30 years. Despite this, relatively scant attention has been paid to individual dose requirements and laboratory control is not a routine request as in the case of oral anticoagulants. Two questions still require an answer. Is laboratory control desirable at all and, if it is, what form should this take? This paper examines these questions on the basis of experience with 50 patients treated with intravenous heparin for a variety of different thromboembolic diseases.

Classical laboratory control is with the whole blood clotting time. It is often said that this should be prolonged to between one and a half and three and a half times the normal value for the individual. On intermittent intravenous injection the test should be taken just before the next dose is due. It is not clear whether the same criteria should be used for continuous heparin infusion. The clotting time is imprecise, difficult to standardize, and if any degree of accuracy is to be obtained the test must be performed at the bedside and at $37^{\circ} \mathrm{C}$. Few will be content to wait the long time till the endpoint is reached. Since heparin inhibits the action of thrombin many of the standard clotting tests should be affected. Some of these were first examined for their sensitivity to the effect of heparin added to normal plasma. Blood from a series of 50 patients who were receiving heparin infusions was then examined to test these laboratory findings in practice.

'Present address: Royal Free Hospital, Lawn Road, London, NW3 Received for publication 16 November 1970.

\section{Methods}

BLOOD COLLECTION

Blood is collected by clean venepuncture into plastic disposable syringes. Three aliquots, each of $1 \mathrm{ml}$, are immediately placed in clean $10 \mathrm{~mm}$ diameter glass tubes kept at $37^{\circ} \mathrm{C}$ in a portable water bath for determination of the clotting time. A further $1.8 \mathrm{ml}$ of blood is gently mixed with $0.2 \mathrm{ml}$ of $3.8 \%$ trisodium citrate in a plastic tube; later this is centrifuged at $3,000 \mathrm{~g}$ for 15 minutes at $4^{\circ} \mathrm{C}$ to obtain plasma. All tests are performed at $37^{\circ} \mathrm{C}$ within two hours of blood collection. Imidazole buffer, $p \mathbf{H ~ 7 \cdot 4 ,}$ used in the tests was prepared according to the method of Biggs and Macfarlane (1962) and contained $0.585 \mathrm{~g} \mathrm{NaCl} / 100 \mathrm{ml}$.

\section{CLOTTING TIME}

The glass tubes are each tilted gently at half-minute intervals. The average of the time taken for each tube to reach the point where the blood would not $ᄋ$ move when the tube was completely inverted is $N$ taken as the clotting time.

PROTHROMBIN TIMES

The one-stage prothrombin time using rabbit brain thromboplastin and the partial thromboplastin time $\stackrel{\oplus}{?}$ with kaolin using inosithin are performed in duplicate 0 according to Hardisty and Ingram (1965).

THROMBIN CLOTTING TIME Human thrombin (Fibrindex, Ortho) is dissolved in 
0.025 molar calcium chloride to a dilution where $0.1 \mathrm{ml}$ of thrombin solution mixed with $0.1 \mathrm{ml}$ of normal plasma gives a clotting time between 10 and 15 seconds. This is usually equivalent to $2.5 \mathrm{NIH}$ units $/ \mathrm{ml}$.

PROTAMINE SULPHATE TITRATIONS OF PLASMA HEPARIN

These are performed by a slight modification of the method of Hardisty and Ingram (1965). Dilutions of protamine sulphate (Boots) are prepared to contain $0.125,0.5,0.75,1.0,1.5$, and $2.0 \mathrm{mg} / 100 \mathrm{ml}$ of imidazole buffer. Mixtures of $0.1 \mathrm{ml}$ of protamine dilution with $0.1 \mathrm{ml}$ of test plasma are prepared in a series of $10 \mathrm{~mm}$ diameter glass tubes at $37^{\circ} \mathrm{C}$ and the clotting time of the mixture is determined from the moment of the addition of $0.1 \mathrm{ml}$ of thrombin, prepared as for the thrombin clotting time. The plasma heparin, as $\mathrm{mg} / 100 \mathrm{ml}$, is taken as equal to that of the protamine dilution which would correct the thrombin clotting time of the mixture to within 10 seconds of normal plasma, assuming that $1 \mathrm{mg}$ of protamine will neutralize $1 \mathrm{mg}$ of heparin. Additions of known quantities of heparin (Weddell, bovine origin), taking $1 \mathrm{mg}$ as equal to 100 units, were used to control the accuracy of the test.

\section{EFFECT OF HEPARIN ON TESTS}

The effect of heparin on the other tests was measured after the addition of $0.1 \mathrm{ml}$ of a heparin dilution in imidazole buffer to $1 \mathrm{ml}$ of citrated blood or plasma.

\section{Patients}

The patients tested all began treatment with a drip infusion of physiological saline or $5 \%$ dextrose in $0 \cdot 18 \%$ saline, containing 20,000 units of heparin in each $500 \mathrm{ml}$ timed to be given in 12 hours. The first day dose of 40,000 units was then altered if necessary on clinical grounds, or if the plasma heparin was found to be undetectable. In the later cases the dose was reduced if at any time the plasma heparin level exceeded $1 \mathrm{mg} / 100 \mathrm{ml}$.

\section{Results}

Heparin additions in vitro prolonged all the tests but with a varying degree of sensitivity (Table I). The results are the average of those obtained with the blood of three normal subjects. The prothrombin time is seen to be the least sensitive but thrombin clotting time and partial thromboplastin time with kaolin are rather more sensitive than the whole blood clotting time. Since the thrombin clotting time takes on the whole a shorter time to perform it was chosen for extended study.

\begin{tabular}{lllll}
\hline $\begin{array}{l}\text { Heparin } \\
\text { Added to } \\
\begin{array}{l}\text { Plasma } \\
(\mathrm{mg} / 100 \mathrm{ml})\end{array}\end{array}$ & $\begin{array}{l}\text { Clotting } \\
\text { Time } \\
(\mathrm{min})\end{array}$ & $\begin{array}{l}\text { Prothrombin } \\
\text { Time } \\
(\mathrm{sec})\end{array}$ & $\begin{array}{l}\text { Partial } \\
\text { Thrombo- } \\
\text { plastin Time } \\
(\mathrm{sec})\end{array}$ & $\begin{array}{l}\text { Thrombin } \\
\text { Clotting } \\
\text { Time }(\mathrm{sec})\end{array}$ \\
\hline $\mathrm{Nil}$ & 4 & 15 & 37 & \\
0.1 & 4 & 15 & 49 & 12 \\
0.2 & 6 & 15 & 60 & 16 \\
0.5 & 13 & 15 & 95 & 22 \\
1.0 & 25 & 17 & 160 & 110 \\
2.0 & $60+$ & 23 & $300+$ & $300+$ \\
\hline
\end{tabular}

Table I Results of adding heparin to plasma

Simultaneous determinations of the clotting time, prothrombin time, thrombin clotting time, and plasma heparin equivalent as measured by the protamine titration were obtained with 21 samples from patients. When these were grouped according to the plasma heparin results the insensitivity of the prothrombin time was confirmed. This was prolonged by one or two seconds only with concentrations of heparin up to $1 \mathrm{mg} / 100 \mathrm{ml}$ and was usually over 30 seconds only with plasma heparin greater than $2 \mathrm{mg} / 100 \mathrm{ml}$. The prothrombin time was, however, much more sensitive if the patient was at the same time receiving oral anticoagulants; the effects were then rather unpredictable, and such patients have been excluded from the analysis. The clotting time

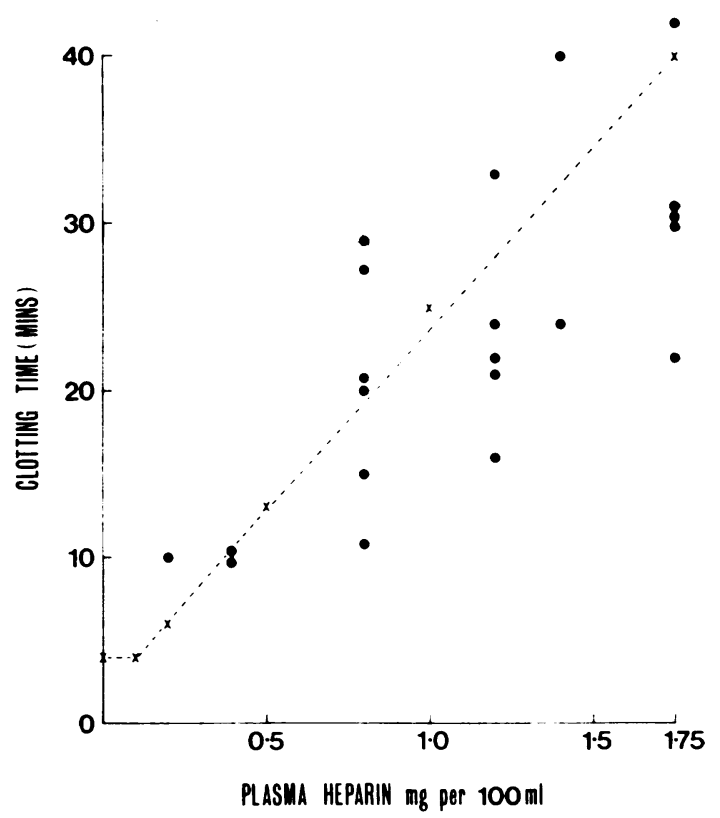

Fig. 1 Plasma heparin level determined by protamine titration.

$\mathrm{x} \ldots \mathrm{x}$ Addition of heparin in vitro to normal plasma - Heparinized patients. 


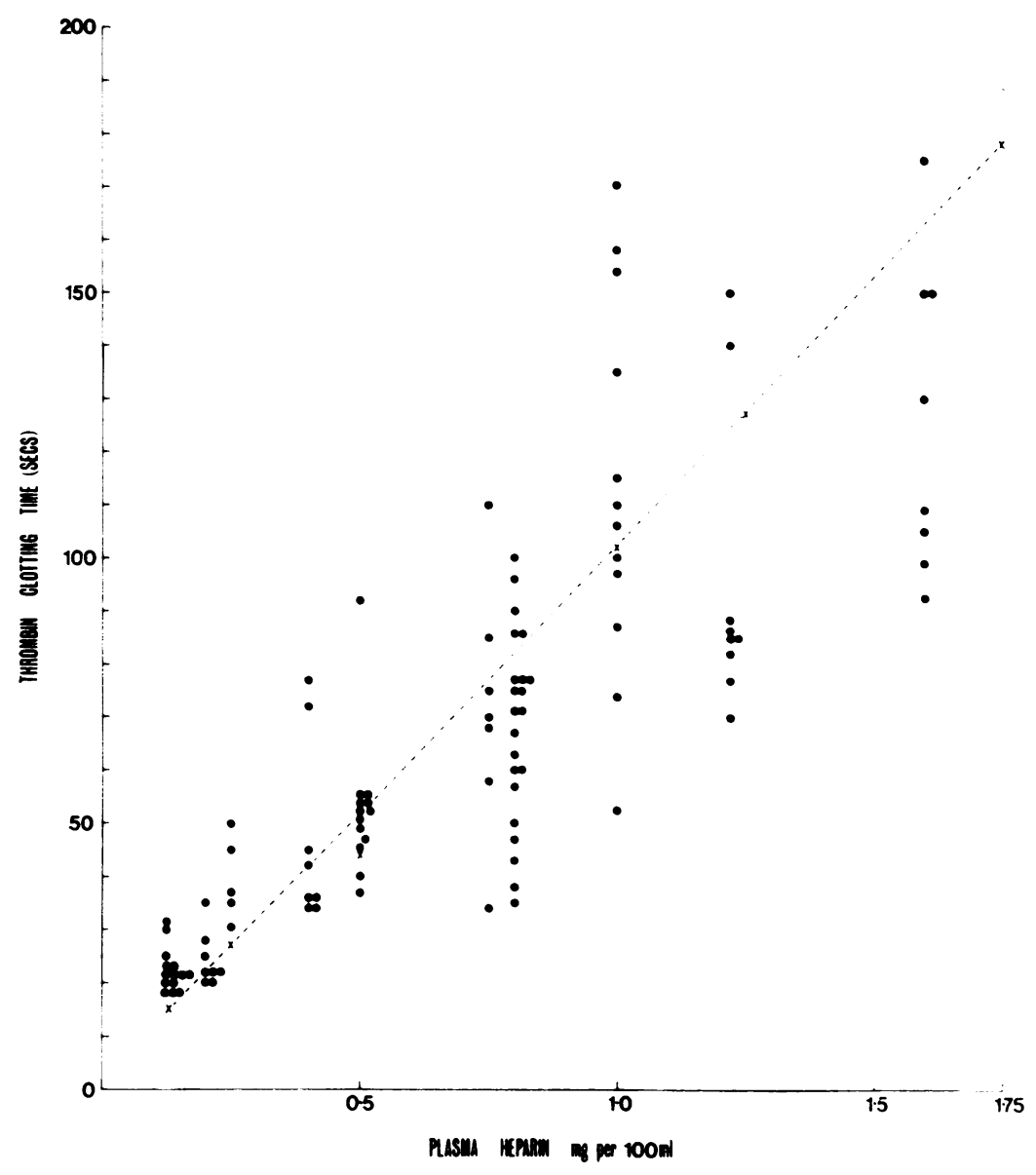

Fig. 2 Plasma heparin levels determined by protamine titration in 50 patients.

$\mathrm{x} \longrightarrow \mathrm{x}$ Addition of heparin $\overline{\mathrm{O}}$ in vitro to normal plasma. Heparinized patients.

showed only a rough correlation with the plasma heparin level and much of this discrepancy was ascribed to the fact that the tests were performed by different observers (Figure 1). The best correlations were between the thrombin clotting time and the plasma heparin and these were extended to a total of 116 observations in 50 patients (Figure 2). Table II shows these results in more detail.

\begin{tabular}{|c|c|c|c|}
\hline \multirow{2}{*}{$\begin{array}{l}\text { Plasma Heparin } \\
(\mathrm{mg} / 100 \mathrm{ml})\end{array}$} & \multicolumn{3}{|c|}{ Thrombin Clotting Time (sec) } \\
\hline & $\begin{array}{l}\text { Mean } \pm \\
\text { Standard } \\
\text { Deviation }\end{array}$ & Range & $\begin{array}{l}\text { No. of } \\
\text { Observations }\end{array}$ \\
\hline $\begin{array}{l}0.25 \\
0 \cdot 25-0.49 \\
0.5-0.99 \\
1 \cdot 0-1 \cdot 75 \\
1 \cdot 75\end{array}$ & $\begin{array}{r}23 \pm 4 \\
44 \pm 14 \\
64 \pm 19 \\
112 \pm 32 \\
233 \pm 63\end{array}$ & $\begin{array}{c}18-35 \\
30-77 \\
34-110 \\
52-150 \\
151-320\end{array}$ & $\begin{array}{r}23 \\
13 \\
42 \\
29 \\
9\end{array}$ \\
\hline
\end{tabular}

Table II Correlation between thrombin clotting time and plasma heparin

\begin{tabular}{ll}
\hline Plasma Heparin $(\mathrm{mg} / 100 \mathrm{ml})$ & Number of Patients \\
\hline Nil & 8 \\
$0 \cdot 25$ & 4 \\
$0 \cdot 25-0.49$ & 2 \\
$0 \cdot 5-0.99$ & 6 \\
$1 \cdot 0-1 \cdot 75$ & 13 \\
$1 \cdot 75$ & Nil \\
\hline
\end{tabular}

Table III Results after 12-24 hours' infusion of heparin, 20,000 units every 12 hours

Great individual variability was found in the response to the standard dose of 40,000 units given? by continuous infusion over 24 hours. Plasmaco heparin between 12 and 24 hours after starting such $\Phi$ a regime is known for 33 patients (Table III) and ${ }^{+}$ varied between nil and $1.75 \mathrm{mg} / 100 \mathrm{ml}$. These ${ }^{\circ}$ differences appeared to be independent of body weight $\frac{\vec{\Phi}}{\mathbb{D}}$ and urine output, and were accompanied by further $?$ variations in response to the same dose by individual $\stackrel{\odot}{\circ}$ patients. In two patients steadily increasing doses 
failed to give detectable heparin levels even after four days, when much lower doses gave high levels. The general pattern was of reducing dose requirements after the first few days of treatment. Undoubtedly some of these findings could be accounted for by variations in the delivery of the infusion but in many instances other factors must have played a part. No toxic effect other than a tendency to bleeding was noted; five of the 50 patients had serious haemorrhage. A paravertebral haematoma resulting in permanent neurological damage occurred with a plasma heparin of $2 \mathrm{mg} / 100 \mathrm{ml}$. A retroperitoneal haematoma which contributed to the death of a patient occurred at a plasma level of 1.5 $\mathrm{mg} / 100 \mathrm{ml}$. Large subcutaneous haematomas occurred in three further patients, one of whom had haematuria at the same time, with plasma levels of $0.5,1.0$, and $2.0 \mathrm{mg} / 100 \mathrm{ml}$ respectively. On the other hand three patients were followed for five days with a plasma level of at least $2.0 \mathrm{mg} / 100 \mathrm{ml}$ with no sign of bleeding.

\section{Discussion}

Since the discovery of heparin in 1916 by McLean, many of its different and useful properties have been identified and made use of in clinical medicine. A naturally occurring sulphated mucopolysaccharide, it possesses a high electro-negative charge and it is this property which interferes directly with a wide variety of enzyme reactions, among them the action of thrombin on fibrinogen and the activation of Christmas factor (factor IX) by activated factor XI. Other useful biological effects are an antihistamine, lipaemia-clearing action and the inactivation of serotonin.

Heparin may be given by intramuscular, subcutaneous, or intravenous injection, the last being preferred in most acute cases. When heparin is given by intermittent intravenous injection a variable effect is introduced owing to the rapid clearance of heparin from the blood. For 30 minutes or more after the injection of 10,000 units into the average adult the clotting time is often longer than 60 minutes. Thereafter it returns to normal at a rate which is dose dependent, as the heparin is acted upon by tissue heparinases. In many patients on a sixhourly regime of injections the clotting time will have returned to normal before the next dose is given. One is therefore faced with the need for repeated injections evenly spaced at three- or fourhour intervals both by day and night, if extreme changes in clotting time and therefore possibly of anticoagulant effect, are to be avoided. An acceptable alternative supported by Harden (1963) is the administration of heparin by intravenous infusion. Even accepting that without the use of a constant infusion device the rate of delivery of heparin given by gravity drip infusion will vary, it should be possible to ensure continuous action throughout the 24 hours and to monitor the effect by laboratory tests. Amongst the authors who have used the constant infusion method there are wide variations in recommended dosage schedules from 20,000 to 120,000 units daily (Kernohan and Todd, 1966; Gurevich, Thomas, and Stuart, 1967). The continuous intravenous therapy lends itself to the measurement of heparin effect which can later be correlated with clinical effect, and such a step seems necessary if these different opinions are to be reconciled. Our results suggest that the control of dose could be based on the thrombin clotting time of plasma.

Independent of the heparin content, individual differences in the thrombin clotting time might be caused by variations in plasma fibrinogen and antithrombin concentration, in particular due to the presence of fibrin or fibrinogen degradation products. However, the experience with these patients suggests that the thrombin clotting time is sufficiently sensitive to give a reliable indication of the plasma heparin level in most subjects being treated for deep vein thrombosis, pulmonary embolism, or cardiac infarction. The test may be performed on a sample of citrated blood sent to the laboratory, as it is for the prothrombin time test used in the control of oral anticoagulant therapy. It is simple to perform and yields a reproducible result quickly under controlled conditions in the laboratory, preferable to a haphazard estimation of clotting time at the bedside.

The whole scatter of results found using a standard dosage scheme, whatever the cause, whether due to variation in heparin delivery or clearance rate, emphasizes the need for daily monitoring of heparin effect. Without this some patients, perhaps as many as $25 \%$ of those receiving 40,000 units daily, will persistently fail to show any circulating heparin at all. Although this need not imply a complete failure of anticoagulant effect, it seems a fair assumption that one should at least be able to demonstrate some heparin if the maximum benefit is to be derived from this treatment, with all its inconveniences for the patient and its potential danger.

In other patients, initially, or sometimes only after several days of the standard dosage of 40,000 units daily, the plasma heparin may exceed 2 $\mathrm{mg} / 100 \mathrm{ml}$. Values over $1 \mathrm{mg} / 100 \mathrm{ml}$ were certainly associated in this series with a greater risk of bleeding, and it is noteworthy that haematuria stopped in one patient in whom heparin was continued at a reduced dosage giving a concentration less than $1.0 \mathrm{mg} / 100 \mathrm{ml}$. Much higher levels could 
be tolerated, indeed must often be exceeded when intermittent therapy is given. A single injection of 10,000 units to the average adult, assuming a plasma value of 3 litres, may give a plasma heparin level in excess of $3 \mathrm{mg} / 100 \mathrm{ml}$, but this will only be for a short period. It seems that such a level if sustained gives rise to a relatively high risk of bleeding. Haemorrhage occurred in five cases $(10 \%)$ of this series. Reports of this complication vary but some degree of haemorrhage may be present in as many as $25 \%$ of cases treated (Jick, Slone, Borda, and Shapiro, 1968). Tests for heparin control on the day of bleeding complications were made by Pitney, Pettit, and Armstrong (1970), who concluded that in some patients bleeding was related to overdosage but in others the laboratory tests showed a satisfactory or low level of heparin at the time of bleeding.

The actual level of plasma heparin at which to aim must await further trials taking clinical benefit into account. Minor variations in the technique of the thrombin clotting time and the particular type of thrombin employed may well cause differences in interpretation between laboratories. Dilutions of thrombin in imidazole buffer or in calcium chloride gave identical clotting times in citrated plasma samples from many patients and in normal plasma, but in other patients thrombin in imidazole buffer gave greatly prolonged clotting times relative to the samples to which calcium was added. This inconstant phenomenon is difficult to account for and will be the subject of a separate study; complications due to this cause can be avoided by diluting thrombin in calcium chloride solution as described. Probably each laboratory should periodically check the significance of its own results, using the protamine titra- tion, always relating these as far as possible to the clinical benefits obtained and the incidence of bleeding.

Meanwhile, our aim is to ensure that the thrombin듬 clotting time of any patient receiving continuous

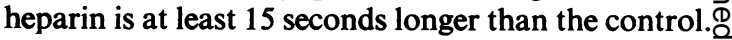
Where a loading dose of 10,000 units is given, followed by a maintenance dose of 40,000 units overs 24 hours, this effect should be achieved. A reduction $?$ in dosage is advised if a time longer than 100 seconds, $\vec{\omega}$ corresponding to a plasma heparin of $1 \mathrm{mg} / 100 \mathrm{ml}$, is detected. Where the complication of haemorrhage? occurs, heparin therapy is stopped immediately and ai citrated blood sample taken for estimation of the thrombin clotting time and the protamine equivalentic of heparin.

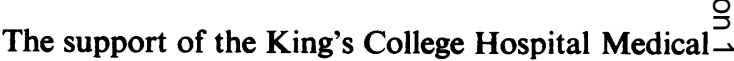
School Research Committee and of Pfizer Ltd is $\%$ gratefully acknowledged.

\section{References}

Biggs, R., and Macfarlane, R. G. (1962). Human Blood Coagulation. Blackwell, Oxford.

Gurevich, V.,Thomas, D. P and Stuart, R. K (1967). Some guidelines for heparin therapy of venous thromboembolic disease. J. Amer. med. Ass., 199, 116-118.

Harden, R. McG. (1963). A method for intravenous administration $\bigcirc$ of heparin in myocardial infarction. Brit. med.J., 2, 1106-1107.

Hardisty, R. M., and Ingram, G. I. C. (1965). Bleeding Disorders. Blackwell, Oxford.

Jick, H., Slone, D., Borda, I. T., and Shapiro, S. (1968). Efficacy and toxicity of heparin in relation to age and sex. New Engl.J. Med., 279, 284-286.

Kernohan, R. J., and Todd, C. (1966). Heparin therapy in thromboembolic disease. Lancet, 1, 621-623.

McLean, J. (1916). The thromboplastic action of cephalin. Amer. J. Physiol., 41, 250-257.

Pitney, W. R., Pettit, J. E., and Armstrong, L. (1970). Control of heparin therapy. Brit. med. J., 4, 139-141. 